\title{
GIS as an Epidemiological Tool to Monitor the Spatial-Temporal Distribution of Tuberculosis in Large Game in a High-Risk Area in Portugal
}

\author{
José Aranha ${ }^{1,2, * \mathbb{D}}$, Ana Carolina Abrantes ${ }^{3} \mathbb{D}$, Raquel Gonçalves ${ }^{4}$, Rui Miranda ${ }^{4}$, João Serejo ${ }^{5}$ and \\ Madalena Vieira-Pinto ${ }^{3,4}$ (i) \\ 1 CITAB, Inov4Agro, University of Trás-os-Montes and Alto Douro (UTAD), Quinta de Prados, \\ 5000-801 Vila Real, Portugal \\ 2 Department of Forestry Sciences and Landscape Architecture (CIFAP), University of Trás-os-Montes and Alto \\ Douro (UTAD), 5001-801 Vila Real, Portugal \\ 3 Veterinary and Animal Science Research Centre (CECAV), University of Trás-os-Montes and Alto \\ Douro (UTAD), 5001-801 Vila Real, Portugal; carolina.psca@gmail.com (A.C.A.); mmvpinto@utad.pt (M.V.-P.) \\ 4 Department of Veterinary Sciences, University of Trás-os-Montes and Alto Douro (UTAD), \\ 5001-801 Vila Real, Portugal; raquelrodriguesgoncalvess@gmail.com (R.G.); \\ rui.miranda.mv@gmail.com (R.M.) \\ 5 Idanha-a-Nova Town Hall, 6060-163 Idanha-a-Nova, Portugal; jmqsp14@gmail.com \\ * Correspondence: j_aranha@utad.pt
}

Citation: Aranha, J.; Abrantes, A.C.; Gonçalves, R.; Miranda, R.; Serejo, J.; Vieira-Pinto, M. GIS as an Epidemiological Tool to Monitor the Spatial-Temporal Distribution of Tuberculosis in Large Game in a High-Risk Area in Portugal. Animals 2021, 11, 2374. https://doi.org/ $10.3390 /$ ani11082374

Academic Editors:

David Cano-Terriza and Jose Manuel Diaz-Cao

Received: 23 June 2021

Accepted: 9 August 2021

Published: 11 August 2021

Publisher's Note: MDPI stays neutral with regard to jurisdictional claims in published maps and institutional affiliations.

Copyright: (c) 2021 by the authors. Licensee MDPI, Basel, Switzerland. This article is an open access article distributed under the terms and conditions of the Creative Commons Attribution (CC BY) license (https:// creativecommons.org/licenses/by/ $4.0 /)$.
Simple Summary: Hunting of large game is an activity of great social and economic importance. However, it can cause public health problems due to the zoonotic diseases of these animals, such as tuberculosis. Regular space-time monitoring of hunted animals' health status allows both the hunters and competent authorities to understand the geographic location of the hunted animals, as well as the occurrence of possible diseases in these animals. This investigation presents the results of the assessment of the spatial-temporal distribution of tuberculosis in large game in a tuberculosis high-risk area in Portugal in the form of maps, which allow any interested party to quickly analyse the hunting situation regardless of their technical or scientific knowledge.

Abstract: Since April 2011, Portugal has implemented specific national legislation (Notice No. 1/2011), defining "Epidemiologic Risk Areas for Bovine Tuberculosis in Large Game" and mitigation measures in these areas, including Idanha-a-Nova county. A GIS project was created to record information that would allow us to analyse the spatial-temporal distribution, both for hunting bags and tuberculosis occurrence, in hunted wild boar and red deer in Idanha-a-Nova. Hunting bag and tuberculosislike lesion data were recorded during post-mortem inspection across 11 hunting seasons, totalling 9844 animals. The difference in tuberculosis occurrence for these species was statistically significant in nearly all 11 seasons, with wild boars presenting approximately twice the occurrence of red deer. No significant difference was noted before and after the Notice No. 1/2011 implementation. These results, following GIS-based spatial analysis, enable us to state that both large game species displayed an irregular tuberculosis pattern for the 2006-2016 period, and we identified some specific areas of high risk for both species. Southern areas of the county may be considered the priority for intervention. This research demonstrates the potential of GIS tools to evaluate, in the field, the results and efficacy of legislation such as Notice No. 1/2011, and to ensure the correct implementation of cost-effective mitigation strategies for tuberculosis in large game species.

Keywords: geostatistical analysis; GIS; large game; red deer; wild boar; wild ungulates

\section{Introduction}

Animal tuberculosis (TB) is a serious animal health issue that has the risk of spreading to humans [1]. TB eradication in cattle is a priority in EU countries [2], and a major 
concern for the Portuguese Veterinary Authority. Portugal has a robust bovine tuberculosis eradication programme in place. Despite the efforts made over the last few years to eradicate bovine $\mathrm{TB}$, several livestock hotspots remain infected. In some regions, difficulties in eradicating TB in cattle could be related to TB occurrence in wildlife (large game animals), as they share common areas, such as water and feed points, as previously presented by some authors [2-5]. This epidemiological scenario led the Portuguese National Veterinary Authority to publish, in April 2011, a specific national legislation (Notice No. 1/2011, from the English translation of Editorial No. 1/2011) defining the "Epidemiologic Risk Areas for Bovine Tuberculosis in Large Game", and describing mandatory rules to be followed in each drive hunt organised within these areas [6].

National scientific research on this subject has been mainly focused on the application of molecular epidemiology techniques, aiming to analyse the possibility of cross-species transmission between wildlife and livestock [7-9]. However, to date, no reports have attempted to evaluate the TB spatial-temporal distribution in large game populations in the Portuguese Epidemiologic Risk Areas for Bovine Tuberculosis.

The combined use of Geographical Information System (GIS), Global Navigation Satellite System (GNSS), and Remote Sensing (RS) technologies is being increasingly explored to study the spatial and temporal patterns of infectious diseases, as well as to contribute to decision support models for disease control [3,8,10-15].

GIS is an interactive tool with great potential to record, manage, and process georeferenced information, and to present research results in map format. In wildlife disease research, it is of capital importance to know about animals' geographical locations, both for endemic disease monitoring and surveillance, and for new disease emergence. GIS integrates spatial analysis tools and geostatistical tools, which allows for analysis of spatial-temporal hunting bag behaviour and monitoring of the effects of disease control strategies [16].

The majority of veterinary research that uses GIS also includes environmental, ecological, topographical, hydrological, climatic, land use, public infrastructure, transportation, and epidemiological data $[13,16,17]$. In veterinary epidemiology, GIS techniques are crucial and useful, as they offer new analytic opportunities for disease assessment and prevention [18], including assessment of the environmental influence, habitat, and risk factors in disease prevalence [13].

GIS-derived results could be used to predict a disease dynamic via spatial occurrences representation. The geographical patterns could be depicted as a colourful map, based on a disease class interval or a continuous scale derived from descriptive statistics, such as disease prevalence $[13,19,20]$, as in the case of TB in Portuguese large game species. As the geodatabase could be updated regularly, new maps representing the current situation could be regularly and continuously updated, allowing disease spatial dynamic surveillance over time [13]. These are important issues in spatial and temporal sampling schema design, and can support control plan implementation. It is important to decrease the risk of transmission and increase an effective response from the perspective of public health [21].

GIS tools allow the creation of maps and spatial representations that could increase the communication efficacy between authorities and stakeholders with responsibilities in wildlife disease control and effect mitigation, such as risks to public health $[19,21]$.

To the best of the authors' knowledge, this work is the first geospatial study performed in Portugal to evaluate the spatial-temporal occurrence of TB in large game, supported by Geographic Information Systems (GIS) and geostatistical analyses. Analysing how animals and disease are geographically distributed in the large game population is essential in the comprehension of the TB dynamic in this relevant Portuguese hunting area.

The authors' main aims for this research were to analyse the spatial-temporal distribution of TB in wild boars and red deer from 2006 to 2016, and the relationship between the hunting bag and the number of TB positive animals-both inter-species and intra-species. The results will be submitted to geostatistical analysis, to identify which areas and species could act as the main source of animal infection, and a major risk for disease transmission, 
of TB. All results will be compared for the period before and after Notice No. 1/2011 [6] implementation, to assess the biophysical results of this TB mitigation procedure.

A GIS project was created to characterise the study area, to store multi-temporal and spatial information on hunting activities, TB occurrence in wild boar and red deer, and its geographical distribution throughout Idanha-a-Nova county, an important hunting region included in the "Tuberculosis high-risk area in Portugal". This project also integrated remote sensing capabilities (RS) to use satellite image tasks and global navigation satellite system capabilities (GNSS) to locate post-mortem inspection actions performed in loco by a veterinarian.

\section{Materials and Methods}

\subsection{Study Area Characteristics}

This research project was carried out within Idanha-a-Nova county (Figure 1), which is located in the central-eastern part of Portugal (lat. $39^{\circ} 55^{\prime} \mathrm{N}$; long. $7^{\circ} 14^{\prime} \mathrm{W}$ ), sharing a border with Spain (Extremadura) and defined by the Erges river on the eastern side and the Tagus river in the south.
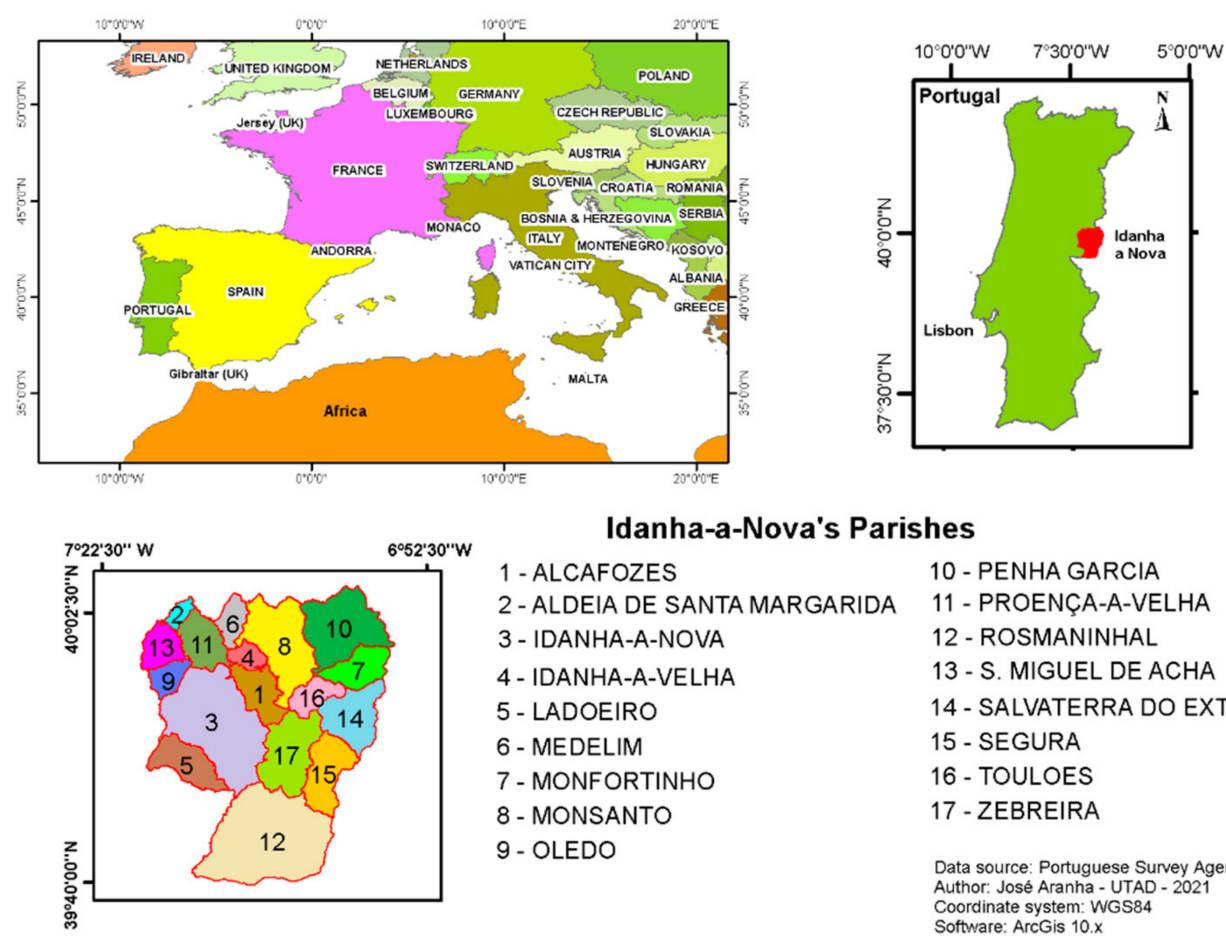

Idanha-a-Nova's Parishes

1 - ALCAFOZES
2 - ALDEIA DE SANTA MARGARIDA
3 - IDANHA-A-NOVA
4 - IDANHA-A-VELHA
5 - LADOEIRO
6 - MEDELIM
7 - MONFORTINHO
8 - MONSANTO
9 - OLEDO

10 - PENHA GARCIA

11 - PROENÇA-A-VELHA

12 - ROSMANINHAL

13 - S. MIGUEL DE ACHA

14 - SALVATERRA DO EXTREMO

15 - SEGURA

16 - TOULOES

17 - ZEBREIRA

Data source: Portuguese Survey Agency, ESRI Author: José Aranha - UTAD - 2021 Software: ArcGis 10.x

Figure 1. Study area location.

This is a $1416.25 \mathrm{~km}^{2}$ rural area, with low human density. The predominant land covers are agriculture $(48.7 \%)$, forestry $(37.6 \%)$, shrubland $(12.1 \%)$, water $(0.9 \%)$, and human infrastructure (0.7\%) [22], as depicted in Figure 2. 


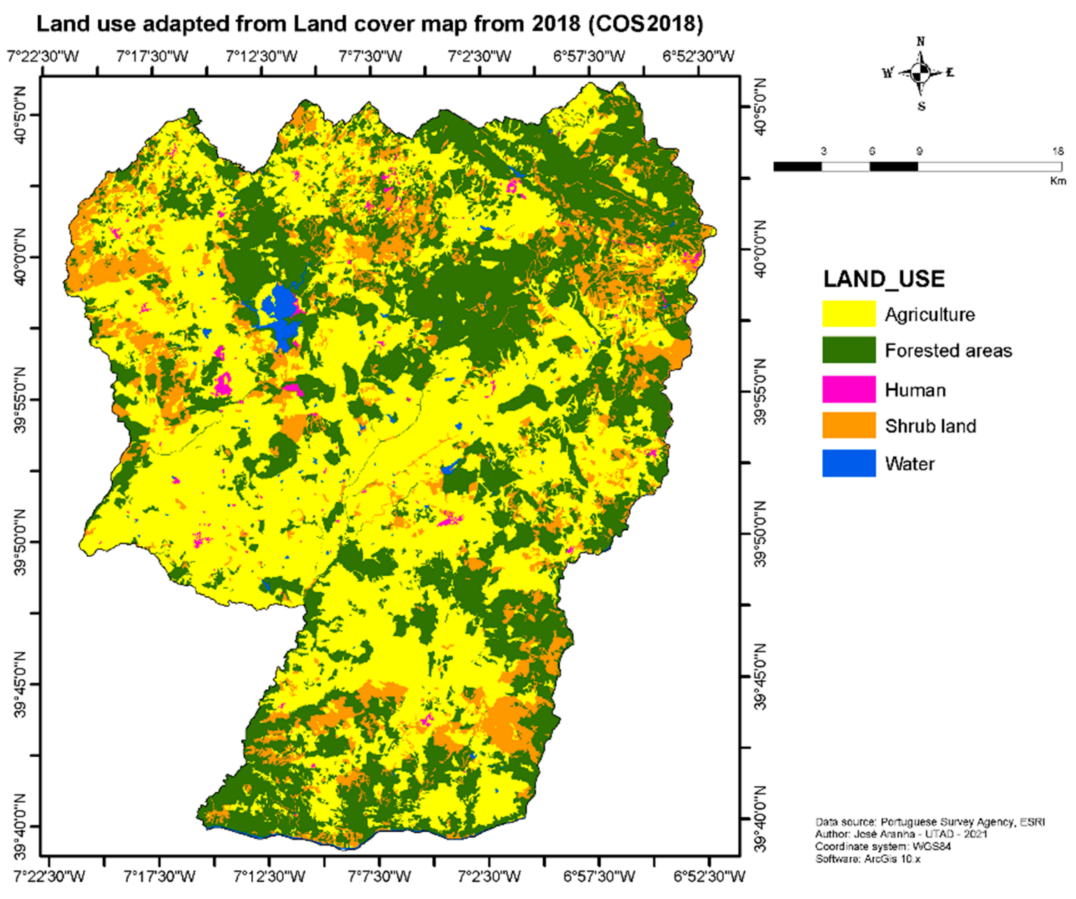

Figure 2. Land-use characteristics of Idanha-a-Nova County in Portugal, adapted from [22].

This county is also known as one of the best places for large game hunting in Portugal. In 2020, 121 hunting estates were located within this county, both with fenced game populations (generally with high densities) or free-ranging populations (not fenced), across about 120,000 hectares of hunting area ( $85 \%$ of the county) [22]. This could be associated with the development of an important commercial hunting industry [8].

By force of Notice No. 1/2011, Idanha-a-Nova county is included in the "Portuguese Epidemiologic Risk Areas for Bovine Tuberculosis in Large Game", due to the high TB prevalence in wild boars and red deer, as already reported in previous research $[7,8,15]$.

\subsection{Data Collection and Processing}

Data were collected from 152 hunting estates across 11 regular hunting seasons (October-February) from 2006 to 2016. Post-mortem inspections of wild boars and red deer was always performed in loco after each drive hunt, by the same veterinarian from the Idanha-a-Nova Town Hall. All hunted animal carcasses and respective viscera were subjected to detailed inspection for gross lesion detection, like the one described by $[8,9,23-25]$. In brief, this involved incision and examination of the retropharyngeal lymph nodes, visual examination and palpation of the lungs, incision and examination of the left bronchial and mediastinal lymph nodes, incision of the mesenteric lymph nodes, and incision of the pre-crural and pre-scapular lymph nodes.

For this study, all caseous or caseoalcareous tubercles with different sizes present in the lymph nodes and organs were considered tuberculosis-like lesions (TBLs). The animal was considered TB positive when at least one TBL was found.

Tuberculosis-like lesion (TBL) occurrence in wild ungulate populations has been employed as a criterion to estimate the occurrence of TB and evaluate the TB distribution [3].

All sampling spots were georeferenced through large game locations using Google Earth and GNSS recorded data.

The population size of individual game species in Idanha-a-Nova was estimated by the reverse calculation method, based on hunting bag statistical analysis [26].

This database was used to calculate the descriptive statistics, Student T-test, Pearson correlation, and for regression analysis [27,28], to analyse the annual hunting bag and TBL occurrence, as well the relationship between these two variables. Non-linear regression models were adjusted by means of the Method of Least Squares (MLS). The adjusted models 
were than ranked according to the lower Root Mean Square Error (RMSE) and the higher adjusted determination coefficient $\left(\mathrm{R} \_\mathrm{adj}^{2}\right)$. Statistical analysis and data processing were performed using Microsoft Excel ${ }^{\circledR}$ and the statistical package JMP ${ }^{\circledR}$, from the SAS Institute.

The data regarding the hunting bag and TBL occurrence for wild boars and red deer for each year were submitted for geostatistical analysis using the ArcGIS 10.7 Geostatistical Tool Box, to analyse the spatial hunting bag and TB occurrence spatial distribution within Idanha-a-Nova county [29-32].

\subsection{GIS Project}

A GIS project was created regarding the wild boar and red deer hunting bag and TBL occurrence each year, from 2006 to 2016, to enable cartographic actions, data processing, geostatistical analysis, and map creation [3,8,11-13,15,29-32].

The database used to derive this research was composed of both binary variables (e.g., sanitary condition: positive or negative to $\mathrm{TB}$ ) and by quantitative continuous variables (e.g., number of hunted animals, number of positive animals). It was necessary to estimate TB occurrence in large game, both for wild boars and red deer, and to analyse its spatialtemporal distribution, according to the research aims.

Geostatistical analysis was performed for each year in the analyses within Idanhaa-Nova county, and for each species [29-32]. The calculation was undertaken for the annual hunting bag and the TBL occurrence. The results from the interpolation processes were represented by a colour ramp, which has previously been standardised [30-32], to create a continuous map related to the annual hunted animals and disease spread for the Idanha-a-Nova county.

\section{Results}

From 2006 up to 2016, 152 hunting sessions were surveyed in Idanha-a-Nova county, which involved 9844 animals (3963 wild boar and 5881 red deer). Estimation of the TB distribution and occurrence in these ungulate populations was based on TBL detection during post-mortem inspection after each drive hunt. The results are presented in Table 1.

Table 1. Hunting bags of wild boar and red deer and TB occurrence, for the period 2006-2016.

\begin{tabular}{|c|c|c|c|c|c|c|}
\hline \multirow[b]{2}{*}{ Year } & \multicolumn{2}{|c|}{ Wild Boar } & \multicolumn{4}{|c|}{ Red Deer } \\
\hline & $\begin{array}{c}\text { Hunting } \\
\text { Bag (N) }\end{array}$ & $\begin{array}{l}\text { (1) Affected } \\
\text { Carcasses (N) }\end{array}$ & $\begin{array}{l}\text { (2) Occurrence } \\
\text { (95\% C.I.) }\end{array}$ & $\begin{array}{c}\text { Hunting } \\
\text { Bag (N) }\end{array}$ & $\begin{array}{l}\text { (1) Affected } \\
\text { Carcasses (N) }\end{array}$ & $\begin{array}{l}\text { (2) Occurrence } \\
\text { (95\% C.I.) }\end{array}$ \\
\hline 2006 & 202 & 20 & $9.9( \pm 9.37)$ & 445 & 35 & $7.9( \pm 6.48)$ \\
\hline 2007 & 171 & 7 & $4.1( \pm 9.49)$ & 324 & 30 & $9.3( \pm 7.07)$ \\
\hline 2008 & 287 & 42 & $14.6( \pm 11.52)$ & 571 & 45 & $7.9( \pm 8.86)$ \\
\hline 2009 & 261 & 56 & $21.5( \pm 11.88)$ & 397 & 58 & $14.6( \pm 11.37)$ \\
\hline 2010 & 462 & 85 & $18.4( \pm 14.08)$ & 563 & 56 & $9.9( \pm 11.47)$ \\
\hline 2011 & 452 & 89 & $19.7( \pm 12.52)$ & 861 & 107 & $12.4( \pm 20.12)$ \\
\hline 2012 & 458 & 99 & $21.6( \pm 12.30)$ & 827 & 74 & $8.9( \pm 14.44)$ \\
\hline 2013 & 385 & 54 & $14.0( \pm 7.85)$ & 514 & 46 & $8.9( \pm 6.71)$ \\
\hline 2014 & 506 & 58 & $11.5( \pm 10.18)$ & 442 & 20 & $4.5( \pm 2.63)$ \\
\hline 2015 & 371 & 64 & $17.3( \pm 14.22)$ & 374 & 54 & $14.4( \pm 9.22)$ \\
\hline 2016 & 408 & 73 & $17.9( \pm 10.18)$ & 563 & 45 & $8.0( \pm 3.20)$ \\
\hline Total & 3963 & 647 & - & 5881 & 570 & - \\
\hline Avg. & 360.3 & 58.8 & $16.4( \pm 15.14)$ & 534.6 & 51.8 & $9.7( \pm 8.85)$ \\
\hline Std. & 113.4 & 28.2 & & 173.5 & 23.4 & \\
\hline
\end{tabular}

(1) Animals hunted, inspected, and presenting at least one TBL. (2) Occurrence determined by gross pathology. C.I.-Confidence interval; Avg.-Average; Std-Standard deviation. White and grey boxes are related to years before and after application of Notice No. $1 / 2011$, respectively.

Based on Table 1, it is possible to state that in Idanha-a-Nova county, red deer are more frequently hunted than wild boar but, regarding TBL occurrence, wild boar is the 
species with the highest values. The results showed that the implementation of Notice No. 1/2011 [6] led to an immediate decrease in TB occurrence in both species.

Student's T-test was carried out to analyse the statistical significance of TB occurrence within the wild boar hunting bag, within the red deer hunting bag, and between wild boar and red deer, before and after Notice No. 1/2011 [6] was introduced. The results presented in Table 2 show that no statistically significant differences were found for TB occurrence within the same species. Significant results only were found for TB occurrence between wild boar and red deer for 2011 and 2012.

Table 2. Results of the Student's $t$-tests for the period 2010-2013.

\begin{tabular}{|c|c|c|c|c|c|c|c|c|}
\hline & & Wb_10 & Wb_11 & Wb_12 & Rd_10 & Rd_11 & Rd_12 & Rd_13 \\
\hline \multirow[t]{2}{*}{ Wb_10 } & $t$-test & & & & 1.243 & & & \\
\hline & $p$-value & & & & 0.121 & & & \\
\hline \multirow[t]{2}{*}{ Wb_11 } & $t$-test & 0.869 & & & & 2.647 & & \\
\hline & $p$-value & 0.199 & & & & 0.011 & & \\
\hline \multirow[t]{2}{*}{ Wb_12 } & $t$-test & & 0.250 & & & & 2.151 & \\
\hline & $p$-value & & 0.403 & & & & 0.028 & \\
\hline \multirow[t]{2}{*}{ Wb_13 } & $t$-test & & & 1.101 & & & & 0.132 \\
\hline & $p$-value & & & 0.142 & & & & 0.449 \\
\hline \multirow[t]{2}{*}{ Rd_10 } & $t$-test & & & & & & & \\
\hline & $p$-value & & & & & & & \\
\hline \multirow[t]{2}{*}{ Rd_11 } & $t$-test & & & & 0.093 & & & \\
\hline & $p$-value & & & & 0.464 & & & \\
\hline \multirow[t]{2}{*}{ Rd_12 } & $t$-test & & & & & 1.136 & & \\
\hline & $p$-value & & & & & 0.138 & & \\
\hline \multirow[t]{2}{*}{ Rd_13 } & $t$-test & & & & & & 1.343 & \\
\hline & $p$-value & & & & & & 0.099 & \\
\hline
\end{tabular}

Wb-Wild boar; Rd-Red deer.

As previously presented in Table 1, the number of hunted red deer was, in general, higher than the number of hunted wild boar, and this difference was significant at $95 \%$ $(t$-student $=2.7897, p$-value $=0.0126)$. The graphical representation, Figure 3 , shows an alteration in the number of hunted red deer throughout the 11 years, which was opposite to that of wild boar.

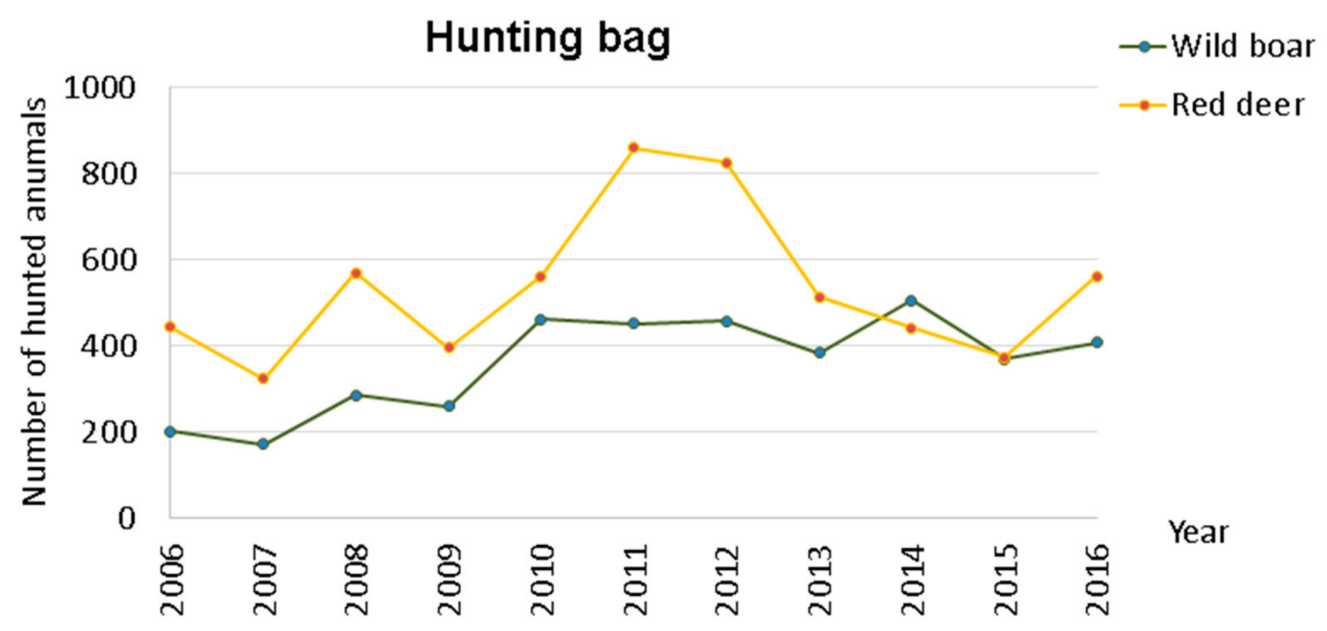

Figure 3. Hunting bag variation within Idanha-a-Nova county from 2006 to 2016.

However, when the global TBL occurrence is calculated for both species (Figure 4), the numbers reveal that occurrence in wild boar is higher than in red deer, and this difference is statistically significant $(t$-student $=3.1095, p$-value $=0.0067$ ), with wild boars having approximately twice the occurrence. 


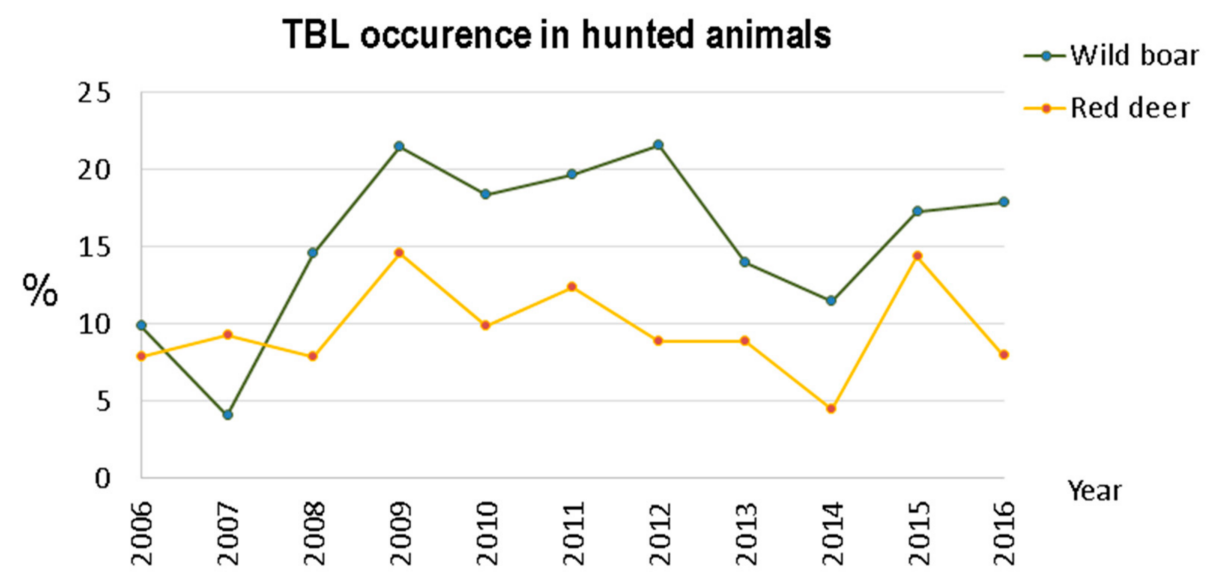

Figure 4. TBL occurrence in the hunting bags within Idanha-a-Nova county from 2006 to 2016.

Both for wild boar and red deer, an irregular disease pattern occurred in the 2006-2016 period. For wild boar, two peaks were observed: the first in 2009, and the second in 2012. The red deer population presented two peaks as well, one in 2009 and a second in 2015. In 2013-2014, we observed a decrease in TBL occurrence in both ungulates.

However, in the years 2015 and 2016, four years after Notice No. 1/2011 [6] was introduced, the TBL occurrence increased again, especially for wild boar. These figures may indicate some relaxation regarding the application of good practices, requiring the implementation of control policies for the effective mitigation of TB in large game species.

In the second stage, the data were subjected to correlation analysis and regression analysis to check whether there was a relationship between the number of hunted animals and the number of TBL-positive animals, both inter-species and intra-species. The results revealed a very significant correlation between the number of hunted animals and the number of TBL-positive animals for both species $(r=0.683, p$-value $<0.05)$, as presented in Table 3.

Table 3. Results after correlation analysis for 2006-2016.

\begin{tabular}{ccccc}
\hline Pearson Correlation & Wb_Ht & Wb_TBL & Rd_Ht & Rd_ TBL $^{+}$ \\
\hline Wild boar hunted (Wb_Ht) & 1 & & & \\
Wild boar TBL positive (Wb_TBL) & $0.854^{* *}$ & 1 & & \\
Red deer hunted (Rd_Ht) & $0.569^{\mathrm{ns}}$ & $0.741^{* *}$ & 1 & \\
Red deer TBL positive (Rd_TBL) & $0.348^{\mathrm{ns}}$ & $0.683^{*}$ & $0.790^{* *}$ & 1 \\
\hline
\end{tabular}

Statistical significance-ns: non-significant, $p$-value $>0.05 ;{ }^{*}$ significant $p$-value $<0.05 ;{ }^{* *}$ very significant $p$-value $<0.01$.

These results are in accordance with previously presented results for Spain and France $[25,33-35]$, and were adjusted by several regression models $[27,28]$ to the pairs of hunted animals/TBL-positive animals. For both species, the semi-logarithm regression model was the one that better fit these value pairs, as presented in Equations (1) and (2).

$$
\mathrm{Wb} \_\mathrm{TBL}^{+}=-339.654+68.268 \times \ln \left(\mathrm{Wb} \_\mathrm{Ht}\right)
$$

$\mathrm{R}^{2}$ adj $=0.7492, p$-value $<0.001$

$$
\mathrm{Rd}_{-} \mathrm{TBL}^{+}=-298.783+56.210 \times \ln \left(\mathrm{Rd} \_\mathrm{Ht}\right)
$$

$\mathrm{R}^{2}{ }_{\text {adj }}=0.4919, p$-value $<0.01$

Annual totals were disaggregated to the parish level, to enable detection of whether the whole county showed the same behaviour, or if there were discrepancies between parishes. The graphical representations show that wild boars are hunted all over Idanha-a-Nova county (Figure 5, top), but red deer are mainly hunted in three parishes (Figure 5, bottom). 


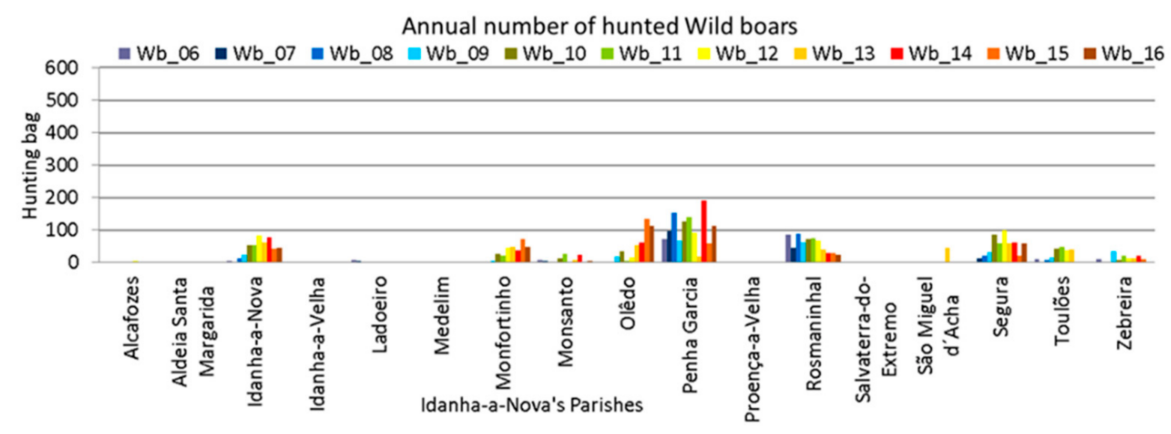

Annual number of hunted Red deers

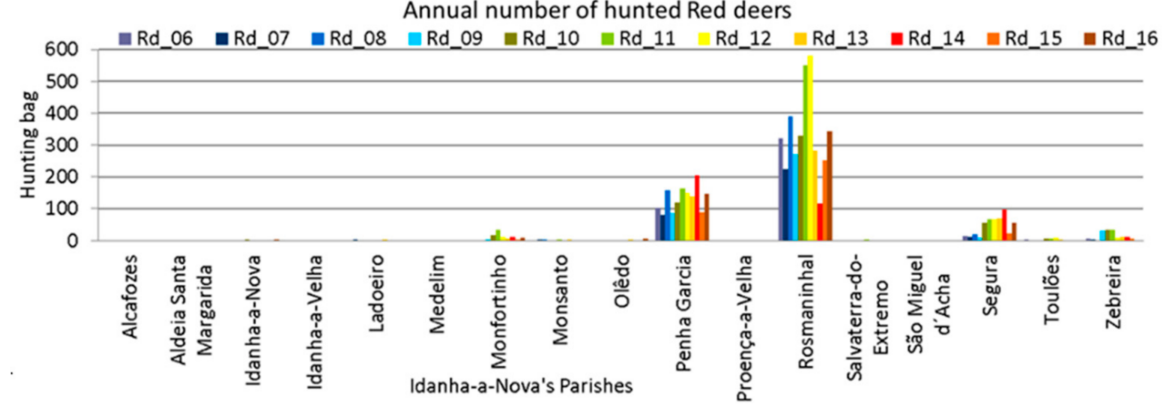

Figure 5. Hunting bag variation across Idanha-a-Nova's parishes from 2006 to 2016. (top): wild boar; (bottom): red deer.

The same disaggregation data were used for TBL occurrence. The graphical representation showed that TBL occurrence in wild boars (Figure 6, top) across Idanha-a-Nova's parishes seems to be consistent with the hunting bags. On the contrary, TBL occurrence in red deer (Figure 6, bottom) mainly occurs in two parishes: Rosmaninhal and Segura (southern region).
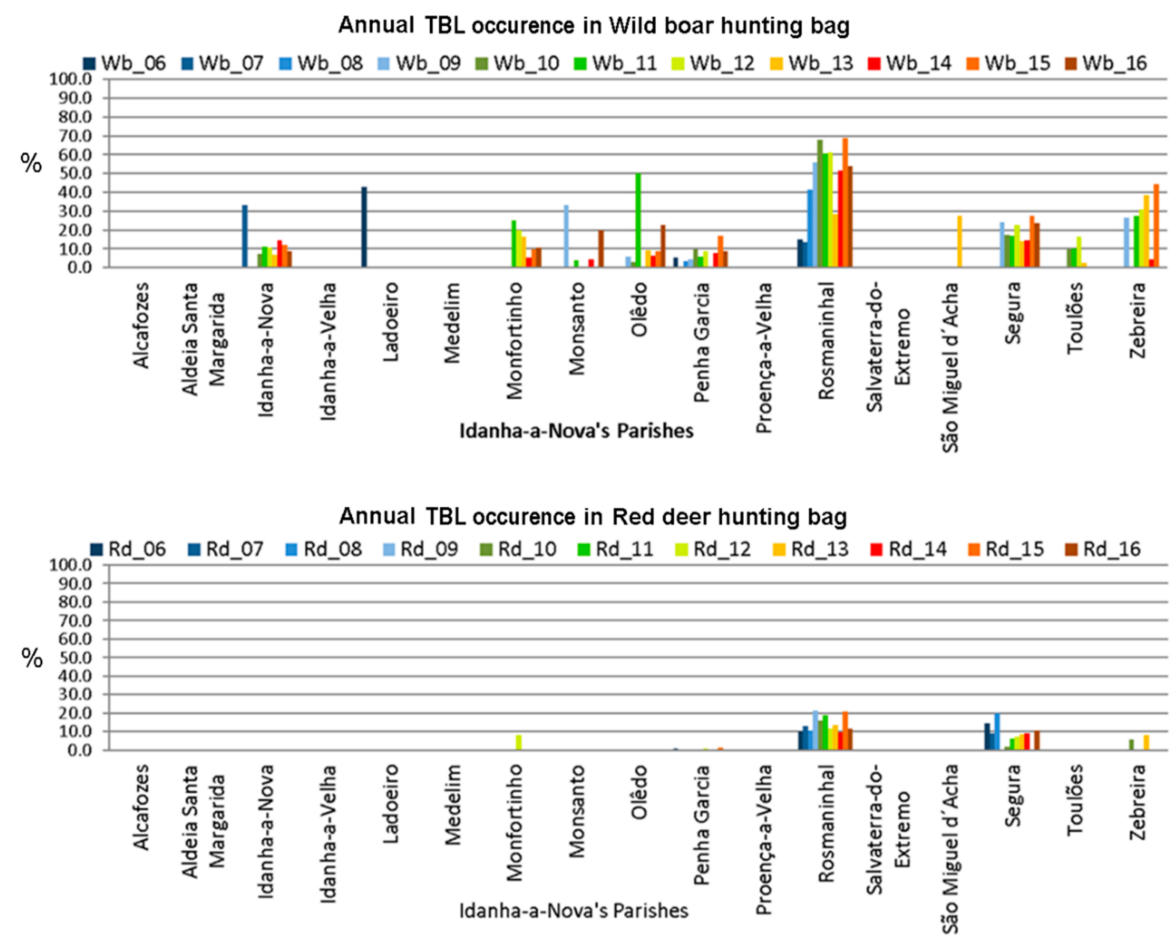

Figure 6. TBL occurrence variation across Idanha-a-Nova's parishes from 2006 to 2016. (top): wild boar; (bottom): red deer. 
When comparing these two graphical representations by parish, and once we know that in this scenario the contact rate between TB hosts increases equally $[28,29]$, it can be formulated that high densities of animals could increase the potential intra- and interspecies transmission of this infectious agent.

In the third stage analysis, all data were subjected to geostatistical techniques and the Inverse Distance Weighted (IDW) interpolation [29-32], to create continuous maps related to the hunting bag and TBL occurrence. The IDW method was used as there were only 17 sampling sites available, and this number is not sufficient for the Kriging interpolation process.

The results, presented in Figure 7 (top: wild boar; bottom: red deer), enable us to state that wild boars are the most widely distributed within Idanha-a-Nova county. The red deer population seems to be more concentrated in the southern and northeastern areas (Rosmaninhal and Segura), and in the northeast (Penha Garcia).

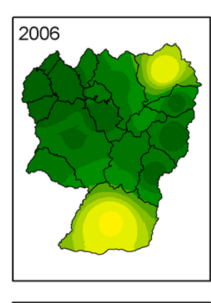

Wild boar hunting bag spatio-temporal distribution 2006-2016
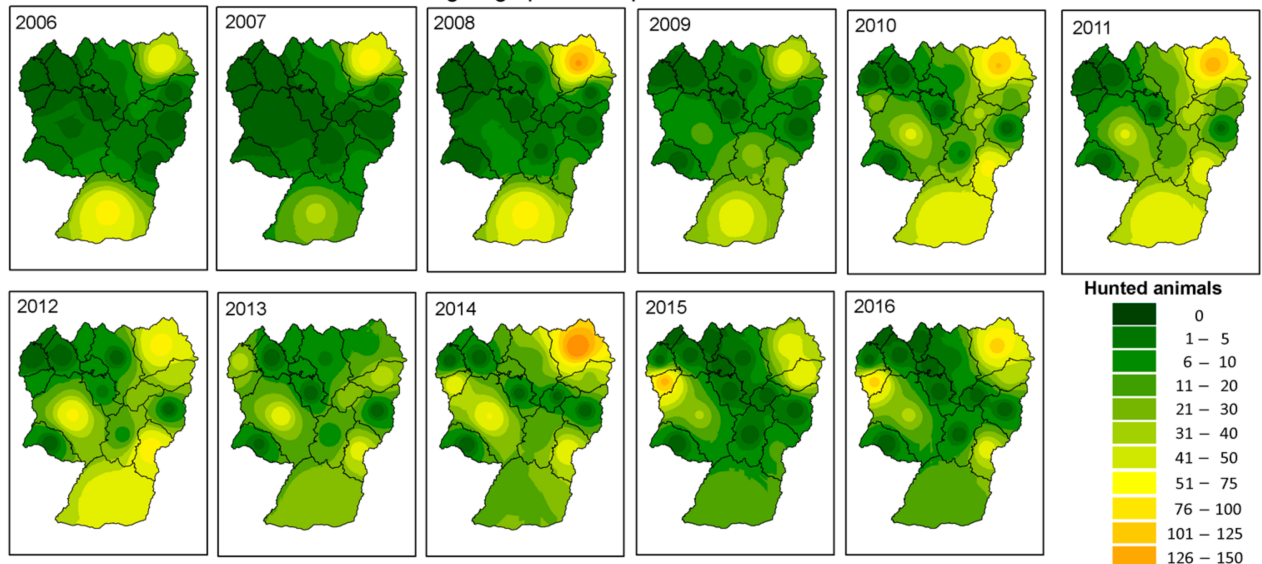

Hunted animals

Red deer hunting bag spatio-temporal distribution 2006-2016
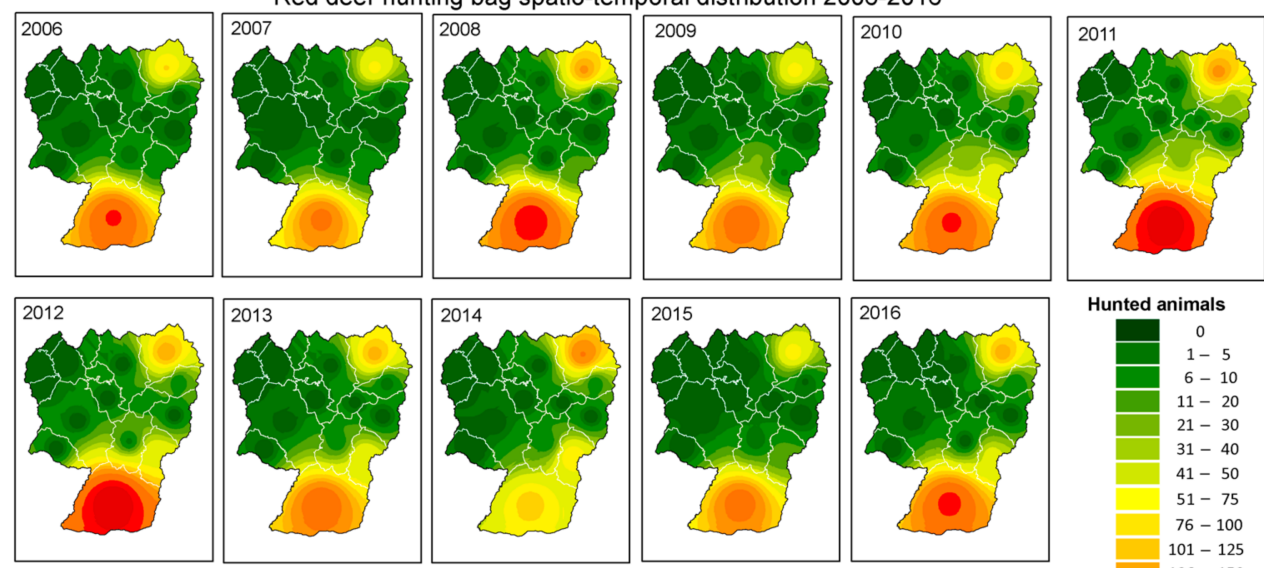

Hunted animals

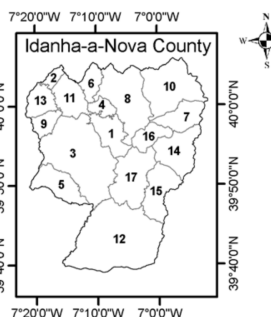

$$
\begin{aligned}
& \text { Idanha-a-Nova's Parishes } \\
& \text { 1-ALCAFOZES } \\
& \text { 2-ALDEIA DE SANTA MARGARIDA } \\
& \text { 3- IDANHA-A-NOVA } \\
& \text { 4- IDANHA-A-VELHA } \\
& \text { - LADOEIRO } \\
& \text { 6-MEDELIM } \\
& \text { 7- MONFORTINHO } \\
& \text { 8-MONSANTO } \\
& \text { 9- OLEDO }
\end{aligned}
$$

10 - PENHA GARCIA

11 - PROENÇA-A-VELHA

12 - ROSMANINHAL

13 - S. MIGUEL DE ACHA

14 - SALVATERRA DO EXTREMO

15 - SEGURA

16 - TOULOES

17 - ZEBREIRA

Figure 7. Hunting bag spatial-temporal distribution within Idanha-a-Nova county from 2006 to 2016. (top): wild boar; (bottom): red deer.

Despite wild boars being present all over the county, it was noted that they also occur in higher numbers in three parishes (Rosmaninhal, Segura, and Penha Garcia). 
As shown in Figure 7, the Penha Garcia parish is a hot spot regarding the hunting bag for both species, followed by the Rosmaninhal parish, although it was in this latter parish that more red deer were hunted.

However, it was not in Penha Garcia that more cases of TBL were detected (Figure 8). The most problematic parishes were located in the south: Rosmaninhal and Segura. As aforementioned, this area presented high values of hunting bags for both species, equating to the cohabitation of a large number of animals.

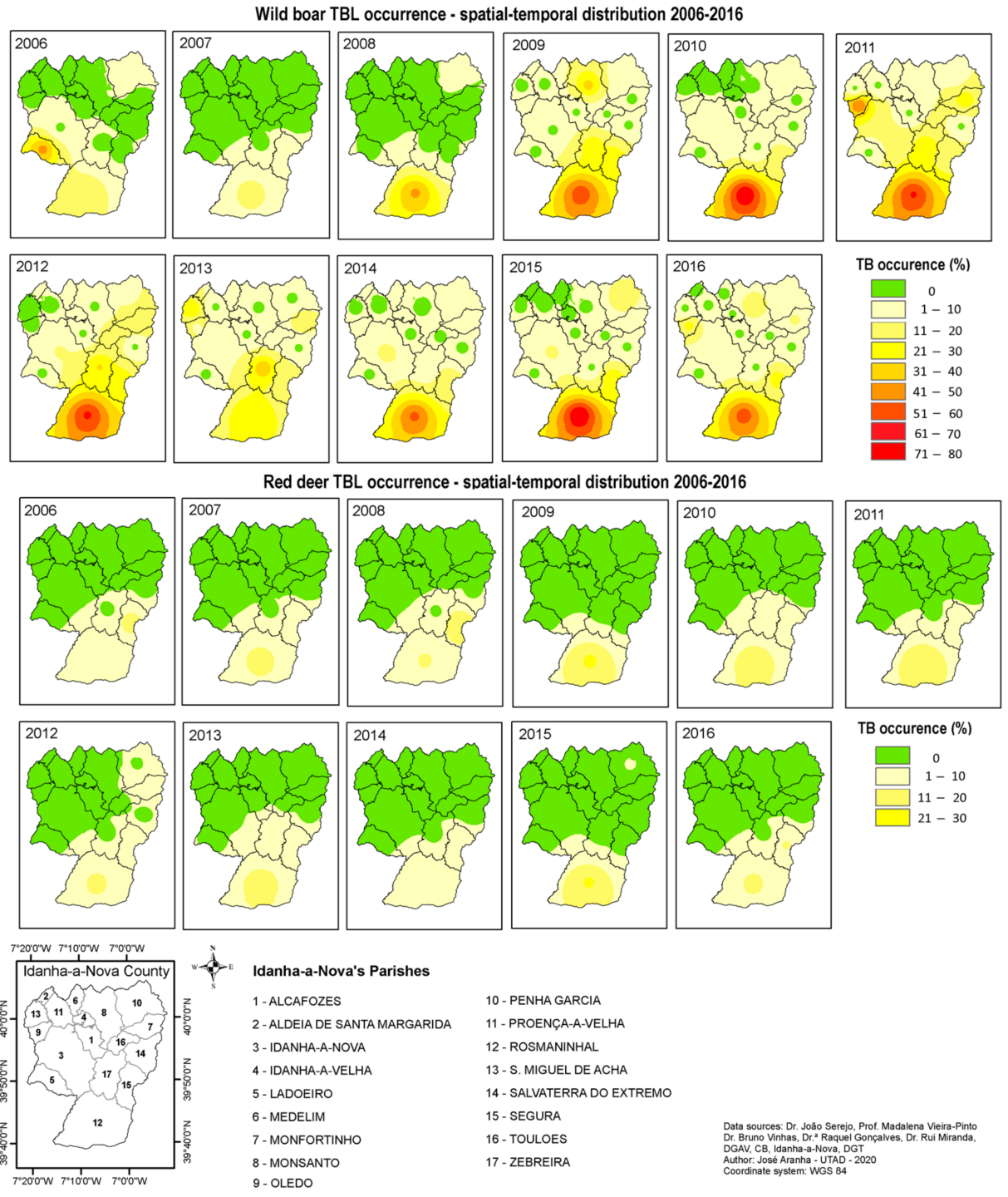

Figure 8. TB occurrence spatial-temporal distribution within Idanha-a-Nova county from 2006 to 2016. (top): wild boar; (bottom): red deer.

\section{Discussion}

According to previous research [25,33-35], high density may favour higher contact rates among TB hosts, which, consequently, may increase TB transmission. Despite our results verifying this statement, we also noted some contradictory outcomes. In the northeast region (Penha Garcia), an equivalently large number of animals presented a lower rate of TBL occurrence in wild boars and just one occurrence in red deer in 2015. Both areas (south and northeast) are hunting states under equivalent game management systems. However, the northeast area is different from the other areas. After GIS-based analysis, it was noted that the northern hunting area was more isolated, with more limited 
animal movement, due to the presence of a densely forested area and a cliff in the south, which limited animal access from surrounding hunting areas.

This provides additional evidence of a potential interaction between several TB hosts when sharing resources, as suggested in previous research. TB prevalence among red deer was significantly associated with TB prevalence among sympatric wild boar [34], which was confirmed by the correlation value $(R=0.683$; $p$-value $<0.05$, see Table 2$)$ between TBL-positive wild boar and TBL-positive red deer per annum in this study.

The results demonstrated that the TBL occurrence in wild boars shows an increasing trend in the south-north direction. Wild boar may play an important role in the emergence of new disease foci in distant areas, but red deer do not seem to have the same potential.

As previously stated by other authors $[25,34,35]$, wild boars seem to be more affected than red deer by a lack of resources, and fences do not impede their movement between estates. Their agility and mobility traits may confer them an important role in TB dispersion within wild or even domestic animals [32]. We noted that the TB occurrence in large game seems to be a severe problem in Idanha-a-Nova county. Presently, it is known that large game species can maintain the disease in the absence of livestock (data not shown), contrary to findings previously described [36-38]. The high number of hunted animals in some parishes could be related to some artificial management practices, which could be the cause of the increase in the large game animal population density. This high density may be responsible for the observed increase of TB infection in this population. Infection could occur direct or indirectly, and is observed mainly at risk points for wild animal aggregation [38,39].

In 2011, the Portuguese veterinary authorities implemented good practices in the field, with the internal law Notice No. 1/2011 [6], for the correct management and elimination of by-products related to carcasses from TBL-positive animals. The results here showed that implementation of Notice No. 1/2011 led to an immediate decrease in TBL occurrence in both species, but this decrease was not statistically significant.

However, in two consecutive years (2015 and 2016) after Notice No. 1/2011 [6] introduction, TBL occurrence increased again, mainly within the wild boar population, reflecting the need to evaluate the efficacy of the practices implemented by force of this legislation. The results presented in this technological study may underline the importance of GIS as a tool to support the adoption of effective priority control measures to decrease the TB occurrence in large game in Idanha-a-Nova and in other regions with similar epidemiological conditions.

This research demonstrated the potential of GIS tools to analyse the spatial-temporal distribution of wild animals and TB infection [40], which could support the implementation of cost-effective mitigation strategies [18].

The GIS project could be successively updated, becoming an essential component of the surveillance system in this studied TB hotspot for the Portuguese large game population. This project could elucidate more about the spatial characteristics of this disease by uploading other modelling components: demography, age-structured disease transmission, and a habitat-dependent movement model.

According to some authors [41], predicting the spread of infections among individuals within groups is likely to be relatively straightforward based on patterns of social and mating behaviour, rates of interaction, and sharing of habitats and resources. Other management strategies, such as culling or vaccination, can be also modelled as modifications of these components, and the results demonstrated in representative GIS maps [40,42,43]. These illustrative maps and model outputs could be used to easily communicate with stakeholders and help organise and prioritise management options in coordination with the authorities [43].

\section{Conclusions}

To the best of the authors' knowledge, this is the first research in Portugal that used information over an extensive period (2006-2016) from GIS techniques to evaluate the 
spatial-temporal dispersion of TBL in large game. TB in large game is a serious and ongoing problem in Idanha-a-Nova.

Based on the results, we can state that wild ungulates, specifically wild boar, can act as a true reservoir of TB within wildlife in Idanha-a-Nova, and play an important role in disease dispersion. Reducing TB occurrence in large game is urgently necessary, not only due to the risk of cattle transmission, but also due to the negative impact on the hunting industry, as well to protect public health.

Notice No. 1/2011 implementation led to an immediate decrease of TB in both species, but this was not statistically significant. TBL occurrence in the hunting bag presented a similar pattern before and after this attempt to mitigate the problem. An integrated approach should be developed, which must include application of good practices in large game management (suitable densities, fence placement, use of artificial watering, and feeding), classes on the initial examination of hunted game taught by a veterinarian, and adequate elimination of by-products.

As aforementioned, this study identified some specific areas of increased TB risk in Idanha-a-Nova. The southern areas of the county may be considered as the priority for intervention.

To conclude, GIS and geostatistical analysis are essential tools for surveillance systems of infectious diseases in wildlife. This GIS project is constantly being updated, and constitutes an important instrument to continue understanding and monitoring TB transmission and persistence, to help to cost-effectively control and eradicate this multi-host complex zoonotic disease. Thus, further work should be carried out to address a range of important issues, such as data quality, in order to achieve a better understanding of the population biological characteristics, environmental factors, and anthropogenic behaviours related to the disease epidemiology involving this large game population.

Author Contributions: Conceptualisation, M.V.-P. and J.A.; methodology, M.V.-P.; software, J.A.; validation, M.V.-P. and J.S.; formal analysis, M.V.-P. and J.A.; investigation, M.V.-P., J.S.; R.G., R.M. and A.C.A.; data curation, A.C.A., R.G., R.M., J.S. and M.V.-P.; writing-original draft preparation, J.A.; writing—review and editing, J.A.; visualisation, M.V.-P. and A.C.A.; supervision, M.V.-P.; project administration, M.V.-P.; funding acquisition, M.V.-P. and J.A. All authors have read and agreed to the published version of the manuscript.

Funding: This work was supported by National Funds by FCT, the Portuguese Foundation for Science and Technology, under the project UIDB/04033/2020. The participation of the co-author and project leader, Professor Madalena Vieira-Pinto, was financed by FCT, the Portuguese Foundation for Science and Technology, under the project UIDB/CVT/00772/2020.

Institutional Review Board Statement: Ethical review and approval were waived for this study, due to the fact that the authors only attended to the animals' post-mortem inspection process and did not participate in any hunting action.

Data Availability Statement: Data are reserved information of the author João Serejo, the veterinarian from the Idanha-a-Nova that preformed the post-mortem inspections in loco of wild boar and red deer after each drive hunt.

Conflicts of Interest: The authors declare no conflict of interest.

\section{References}

1. Palmer, M.V. Mycobacterium bovis: Characteristics of Wildlife Reservoir Hosts. Transbound. Emerg. Dis. 2013, 60, 1-13. [CrossRef]

2. Martínez-López, B.; Barasona, J.A.; Gortázar, C.; Rodríguez-Prieto, V.; Sánchez-Vizcaíno, J.M.; Vicente, J. Farm-level risk factors for the occurrence, new infection or persistence of tuberculosis in cattle herds from South-Central Spain. Prev. Vet. Med. 2014, 116, 268-278. [CrossRef]

3. Durr, P.A.; Gething, P.W.; Atkinson, P.M.; Sayers, A.R.; McDonald, R.M. Geostatistical interpolation of wildlife disease prevalence determined by road casualty surveys. In Proceedings of the 11th International Symposium on Veterinary Epidemiology and Economics, Cairns, Australia, August 2006; Available online: http://www.sciquest.org.nz/node/63774 (accessed on 23 June 2021).

4. Gortázar, C.; Ferroglio, E.; Höfle, U.; Frölich, K.; Vicente, J. Diseases shared between wildlife and livestock: A European perspective. Eur. J. Wildl. Res. 2007, 53, 241-256. [CrossRef] 
5. Miller, R.S.; Farnsworth, M.; Malmberg, J. Diseases at the livestock-wildlife interface: Status, challenges, and opportunities in the United States. Prev. Vet. Med. 2013, 110, 119-132. [CrossRef] [PubMed]

6. Direção Geral de Veterinária. Plano de Controlo e Erradicação da Tuberculose em Caça Maior. Available online: http:// srvbamid.dgv.min-gricultura.pt/xeov21/attachfileu.jsp?look_parentBoui=2198974\&att_display=n\&att_download=y (accessed on 23 June 2021).

7. Santos, N.; Correia-Neves, M.; Ghebremichael, S.; Källenius, G.; Svenson, S.B.; Almeida, V. Epidemiology of Mycobacterium bovis infection in wild boar (Sus scrofa) from Portugal. J. Wildl. Dis. 2009, 45, 1048-1061. [CrossRef] [PubMed]

8. Vieira-Pinto, M.; Alberto, J.; Aranha, J.; Serejo, J.; Canto, A.; Cunha, M.V.; Botelho, A. Combined evaluation of bovine tuberculosis in wild boar (Sus scrofa) and red deer (Cervus elaphus) from Central-East Portugal. Eur. J. Wildl. Res. 2011, 57, 1189-1201. [CrossRef]

9. Cunha, M.V.; Matos, F.; Canto, A.; Albuquerque, T.; Alberto, J.; Aranha, J.; Vieira-Pinto, M.; Botelho, A. Implications and Challenges of Tuberculosis in Wildlife Ungulates: A Molecular Epidemiology Perspective. Res. Vet. Sci. 2012, 92, 225-235. [CrossRef]

10. Kitron, U.; Kazmierczak, J.J. Spatial analysis of the distribution of Lyme disease in Wisconsin. Am. J. Epidemiol. 1997, 145, 558-566. [CrossRef]

11. Brooker, S.; Michael, E. The potential of geographical information systems and remote sensing in the epidemiology and control of human helminth infections. Adv. Parasitol. 2000, 47, 245-288. [CrossRef]

12. McKenzle, J.S.; Morris, R.S.; Pfeiffer, D.U.; Dymond, J.R. Application of Remote Sensing to Enhance the Control of Wildlife Associated Mycobacterium bovis Infection. Photogramm. Eng. Remote Sens. 2002, 68, 153-159.

13. Pfeiffer, D.U.; Hugh-Jones, M. Geographical information systems as a tool in epidemiological assessment and wildlife disease management. Rev. Sci. Tech. 2002, 21, 91-102. [CrossRef]

14. Nusser, S.M.; Clark, W.R.; Otis, D.L.; Huang, L. Sampling Considerations for Disease Surveillance in Wildlife Populations. J. Wildl. Manag. 2008, 72, 52-60. [CrossRef]

15. Alberto, J.R.; Aranha, J.; Serejo, J.; Amado, A.; Vieira-Pinto, M. The Utility of GIS in Studying the Distribution of Bovine Tuberculosis in Wild Boar (Sus Scrofa) and Red Deer (Cervus Elaphus) in Central Portugal. In Game Meat Hygiene in Focus. Microbiology, Epidemiology, Risk Analysis and Quality Assurance; Paulsen, P., Bauer, A., Vodnansky, M., Winkelmayer, R., Smulders, F.J.M., Eds.; Wageningen Academic Publishers: Wageningen, The Netherlands, 2011; pp. 199-204.

16. French, N.; White, P. The Use of GIS in Modelling the Spatial and Temporal Spread of Animal Diseases. In GIS and Spatial Analysis in Veterinary Science; Durr, P.A., Gatrell, A.C., Eds.; CABI Publishing: Wallingford, UK, 2004.

17. Balamurugan, G.; Ro, N.; Samrat, S.; Kurne, V.; Purwar, D.; Siddarth, D. Applications of GIS in Public Health Risk ReductionArcGIS Approach. In Proceedings of the 12th ESRI India User Conference, Noida, India, 7-8 December 2011 ; p. 11.

18. Pikula, J. GIS as an Epidemiological Tool in the Study of Infectious Diseases. In Proceedings of the World Small Animal Veterinary Association World Congress Proceedings, Prague, Czech Republic, 11-14 October 2006.

19. Norstrøm, M. Geographical Information System (GIS) as a Tool in Surveillance and Monitoring of Animal Diseases. Acta Vet. Scand. 2011, 42, 79. [CrossRef]

20. Dhama, K.; Verma, A.K.; Tiwari, R.; Chakraborty, S.; Vora, S.; Kapoor, S.; Deb, R.; Karthik, K.; Singh, R.; Munir, M.; et al. A perspective on applications of Geographical Information System (GIS): An advanced tracking tool for disease surveillance and monitoring in veterinary epidemiology. Adv. Anim. Vet. Sci. 2013, 1, 14-24.

21. Beard, R.; Wentz, E.; Scotch, M. A systematic review of spatial decision support systems in public health informatics supporting the identification of high risk areas for zoonotic disease outbreaks. Int. J. Health Geogr. 2018, 17, 1-19. [CrossRef]

22. Direcção Geral do Território. COS15: Carta de Ocupação do Solo Para 2015. 2020. Available online: https: / / www.dgterritorio. gov.pt/dados-abertos (accessed on 23 June 2021).

23. Parra, A.; Larrasa, J.; Garcia, A.; Alonso, J.M.; Hermoso de Mendoza, J. Molecular epidemiology of bovine tuberculosis in wild animals in Spain: A first approach to risk factor analysis. Vet. Microb. 2005, 110, 293-300. [CrossRef]

24. Vieira-Pinto, M. Game Meat Hygiene and Safety in Portugal. Section 3 Hygiene in Game Meat Production and Associated Legislation, In Trends in Game Meat Hygiene: From Forest to Fork; Paulsen, P., Bauer, A., Smulders, F.J.M., Eds.; Wageningen Academic Publishers: Wageningen, The Netherlands, 2004; pp. 223-240.

25. Vicente, J.; Höfle, U.; Garrido, J.M.; Fernández-de-Mera, I.G.; Acevedo, P.; Juste, R.; Barral, M.; Gortazar, C. Risk factors associated with the prevalence of tuberculosis-like lesions in fenced wild boar and red deer in south central Spain. Vet. Res. 2007, 38, 451-464. [CrossRef]

26. Plhal, R.; Kamler, J. Analysis of accuracy of hunting plan in the Czech Republic. Acta Univ. Agric. Silvic. Mendel. Brun. 2012, 19, 165-172. [CrossRef]

27. Daniel, W.W.; Cross, C. Biostatistics: A Foundation for Analysis in the Health Sciences; John Wiley \& Sons: Hoboken, NJ, USA, 1987.

28. Smith, G.C.; Cheeseman, C.L. A mathematical model for the control of diseases in wildlife populations: Culling, vaccination and fertility control. Ecol. Model. 2002, 150, 45-53. [CrossRef]

29. Soares, A. Geoestatística Para as Ciências da Terra e do Ambiente; IST Press: Lisboa, Portugal, 2006.

30. Schröder, W. GIS, geostatistics, metadata banking, and tree-based models for data analysis and mapping in environmental monitoring and epidemiology. Int. J. Med. Microbiol. 2006, 296, 23-36. [CrossRef] [PubMed] 
31. Highfield, L.; Ward, M.; Laffan, S. Representation of animal distributions in space: How geostatistical estimates impact simulation modelling of foot-and-mouth disease spread. Vet. Res. 2008, 39, 17. [CrossRef]

32. Acevedo, P.; Quirós-Fernández, F.; Casal, J.; Vicente, J. Spatial distribution of wild boar population abundance: Basic information for spatial epidemiology and wildlife management. Ecol. Indic. 2014, 36, 594-600. [CrossRef]

33. Zanella, G.; Duvauchelle, A.; Hars, J.; Moutou, F.; Boschiroli, M.L.; Durand, B. Patterns of lesions of bovine tuberculosis in wild red deer and wild boar. Vet. Rec. 2008, 163, 43-47. [CrossRef]

34. Vicente, J.; Höfle, U.; Garrido, J.; Fernandez de Mera, I.; Juste, R.; Barral, M.; Gortázar, C. Wild Boar and Red Deer Display High Prevalence of Tuberculosis-Like Lesions in Spain. Vet. Res. 2006, 37, 107-119. [CrossRef] [PubMed]

35. de Mendoza, J.H.; Parra, A.; Tato, A.; Alonso, J.M.; Rey, J.M.; Peña, J.; García-Sánchez, A.; Larrasa, J.; Teixidó, J.; Manzano, G.; et al. Bovine tuberculosis in wild boar (Sus scrofa), red deer (Cervus elaphus) and cattle (Bos taurus) in a Mediterranean ecosystem (1992-2004). Prev. Vet. Med. 2006, 74, 239-247. [CrossRef] [PubMed]

36. Gortazar, C.; Vicente, J.; Gavier-Widen, D. Pathology of bovine tuberculosis in the European wild boar (Sus scrofa). Vet. Rec. 2003, 152, 779-780. [CrossRef]

37. Gortazar, C.; Vicente, J.; Samper, S.; Garrido, J.M.; Fernandez-De-Mera, I.G.; Gavin, P.; Juste, R.A.; Martin, C.; Acevedo, P.; De La Puente, M.; et al. Molecular characterization of Mycobacterium tuberculosis complex isolates from wild ungulates in south-central Spain. Vet. Res. 2005, 36, 43-52. [CrossRef]

38. Corner, L.A. The role of wild animal populations in the epidemiology of tuberculosis in domestic animals: How to assess the risk. Vet. Microbiol. 2006, 112, 303-312. [CrossRef]

39. Cowie, C.E.; Hutchings, M.R.; Barasona, J.A.; Gortazar, C.; Vicente, J.; White, P. Interactions between four species in a complex wildlife: Livestock disease community: Implications for Mycobacterium bovis maintenance and transmission. Eur. J. Wildl. Res. 2016, 62, 51-64. [CrossRef]

40. Moustakas, A.; Evans, M.R. A big-data spatial, temporal and network analysis of bovine tuberculosis between wildlife (badgers) and cattle. Stoch. Env. Res. Risk Assess. 2017, 31, 315-328. [CrossRef]

41. Nunn, C.L.; Thrall, P.H.; Kappeler, P.M. Shared resources and disease dynamics in spatially structured populations. Ecol. Model. 2014, 272, 198-207. [CrossRef]

42. Cross, P.; Getz, W. Assessing vaccination as a control strategy in an ongoing epidemic: Bovine tuberculosis in African buffalo. Ecol. Model. 2006, 196, 494-504. [CrossRef]

43. Cartwright, S.J.; Bowgen, K.M.; Collop, C.; Hyder, K.; Nabe-Nielsen, J.; Stafford, R.; Stillman, R.A.; Thorpe, R.B.; Sibly, R.M. Communicating complex ecological models to non-scientist end users. Ecol. Model. 2016, 338, 51-59. [CrossRef] 